\title{
UnivQual: A holistic scale to assess student perceptions of service
}

\author{
quality at universities
}

\begin{abstract}
The aim of this study is twofold. First, we validate a scale to assess the quality of the university experienced by students (UnivQual). Three main dimensions are envisioned: (i) "curriculum", which refers to the quality of the learning methods and the coordination efforts throughout the whole study period; (ii) "skills development", referring to the skills that students might acquire and (iii) "services and facilities" of the university. Second, we analyze the role of the aforementioned dimensions and their impact on student satisfaction. Results reveal that the "curriculum" dimension is the main antecedent of student satisfaction, whereas "services and facilities" do not play a significant role, although they are necessary to provide good service. The empirical application considers a survey of 2,557 undergraduate students that finished their degrees in 2013 at universities located in the region of Catalonia (Spain). The paper ends with recommendations for university managers and public administration authorities.
\end{abstract}

Keywords: higher education, perceived service quality, student satisfaction, assessment, university governance 


\section{Introduction}

Higher Education Institutions (HEI) are expected to excel at three different missions: teaching, research and knowledge transfer. Recent trends, such as the commercial competition imposed by economic forces, have forced universities to focus on the quality of the service as a way to obtain sustainable competitive advantages (Abdullah 2006; Sohail and Shaikh 2004). This approach highlights the importance of understanding student satisfaction regarding their educational experience (Abdullah 2006). In recent years, the concept of service quality related to satisfaction has stood as a central point for the higher education (HE) system (Abdullah 2006). University managers want to assure and increase their share in this competitive market; however, to do so, they need to ensure student satisfaction, as they are the active recipients of the service and, therefore, can act as advocates or detractors of their university. Moreover, adopting a wider view, the quality of the university system also creates a reputation for the region or the country. Accordingly, not only university managers but also public authorities are interested in preserving and improving the status of their universities. However, evidence suggests that some reforms that have been introduced in recent years in the HE system have acted as barriers rather than as facilitators (Strathdee 2011), signaling the need for a better understanding of how universities work, and an awareness of the specific nature of the HE system in terms of quality assurance.

Within the academic literature on university quality, there is an increasing interest in identifying the antecedents and consequences of customer satisfaction in HEIs (Letcher and Neves 2010; Mahmood 2011; Sultan and Wong 2014). In the quality context, perceived quality is commonly considered an antecedent of student satisfaction (Snipes et al. 2005). However, other studies show different dimensions as antecedent conditions of student satisfaction such as image, service technical quality or functional service quality (Alves and Raposo 2010, 2007). 
Other studies, like Gruber et al. (2010) affirm that student satisfaction is based on a relatively stable person-environment relationship. As for the drivers, they show that students are particularly satisfied with the geographic location of the university and the atmosphere among students. However, students are mostly dissatisfied with the university buildings and the quality of the lecture theaters. More recently, Jain et al. (2013) show the determinants to include seven dimensions: input quality, curriculum, academic facilities, industry interaction, interaction quality, support facilities and non-academic processes. Given this lack of agreement, it is possible to argue that the determinants of student satisfaction in HE are, to some extent, unknown.

Among the HEI stakeholders, students can be considered one of the most important players in assessing university quality, as they are direct recipients of the services that universities offer (Hill 1995). Echoing Dlacic et al. (2014), we consider students as primary customers of HE services. This is so because universities operate in a highly competitive and globalized sphere where there is strong competition for the best students. Therefore, universities are required to provide them an attractive academic offer. In this respect, it is important to note that university rankings are increasingly relying in metrics that consider reputational aspects. For instance, in the Times Higher Education Ranking of Universities the teaching dimension (a measure of the learning experience and quality at a university) explains $30 \%$ of the total score. Similarly, accreditation agencies are also taking into account student satisfaction when assessing university academic programs. Certainly, the HE industry needs to understand the perceived quality of their students in order to attract and sustain the student body in their institution (Kara and Deshields 2004). Service quality from the lens of student satisfaction is a topic that, in recent years, is gaining awareness, being considered "a newly emerging field of concern" for the academic community (Nadiri et al. 2009). 
Nevertheless, we ought not to forget that students are learners. Through the teaching mission, universities provide human capital (graduates, postgraduates and $\mathrm{PhDs}$ ) that aim at satisfying market demands for a qualified workforce. Paraphrasing the work of Sultan and Wong (2014) rewriting "the customer is the king" as "the student is the king" may not be appropriate. Although students pay for a specific service, the primary goal of education is not to delight students but to equip them to be effective professionals. Thus, the service providercustomer relationship that dominates the commercial service sector cannot be directly applied in the higher education setting. However, the adoption of a student-centric approach may encourage the introduction of innovative practices.

Taken all these considerations together, we can conclude that despite students are only one of the multiple stakeholders in the HE system, their assessment and opinions are particularly relevant for the university in which they have enrolled in. Although opinions from other key stakeholders should be listened (e.g. managers, teaching staff, researchers, etc.), this study focuses its attention on the student voice.

According to Brochado (2009), while there is an agreement on the relevance of service quality in HE, the definition of a correct measurement instrument is still a challenge. The existing literature offers numerous scales; however, they tend to be narrowly focused on a particular service (e.g., the library service, the student claim office, international office, etc.) or designed to assess a particular subject taught at the university. Future research efforts are thus needed to better understand how students evaluate their experience at university.

The original contribution of this study is therefore justified by the urgent need to find a scale that considers university service quality from a holistic perspective. In other words, compared to previous studies, our approach not only considers the academic component of the service offering but also other related-features (e.g. general services, facilities and equipment of the university) included in the service package that might shape the overall satisfaction of students. 
In an era of global competition, universities are expanding their academic offer, introducing innovative teaching methods, providing teaching resources to lecturers, and updating the general services of the university, among others. All these services will be considered when students evaluate their experience at the university. In this paper, we aim to address this theoretical and empirical gap by defining and validating a new scale (UnivQual) that could be applied at any university, regardless of the area of knowledge.

Aiming to bring light to this issue, this paper pursues a double objective. First, we define and validate a scale to assess the perceived quality of students once they have completed their university studies. Second, we assess the usefulness of the scale and examine how each of the different dimensions of this scale of university quality contributes to explain student satisfaction. The empirical application considers a survey of 2,557 undergraduate students that finished their degrees in 2013 at universities located in the region of Catalonia (Spain).

The paper is structured as follows. The next section summarizes the current state of assessing university quality in the HE system. The research method is next presented, followed by the results section. The paper ends discussing the main findings and the implications for management and practice. Limitations and possible avenues for future research are also outlined.

\section{Theoretical underpinnings}

\section{Service quality in higher education}

Literature about HEI is rich. Universities have been addressed from many different perspectives; however, little evidence is found when considering HEIs as service industries, and how these institutions ensure and deliver quality to their multiple stakeholders. In this regard, Rowley (1997) advised that, to measure the quality of HEIs, all stakeholder perspectives, from students to the legislators, should be considered. 
Recent research on this topic mainly concentrates on examining customer satisfaction (students) concerning specific services offered at HEIs, such as the library, the cafeteria, the scholarship program or internships, among others, since the student experience involves much more than teaching and learning (Petruzzellis and Romanazzi 2010).

In this field, different techniques are used to assess service quality. Quinn et al. (2009) reviewed the methods and standards used in such studies, and listed the following: Total Quality Management (TQM), Quality Function Deployment (QFD), Six Sigma, ISO 9001, the Malcolm Baldrige National Quality Award, and the Academic Quality Improvement Program (AQIP). As for the specific use of each method, TQM was the approach most widely used (e.g., Ali et al. 2010; Mergen et al. 2000). Moreover, Quinn et al. (2009) also detected that both QFD and ISO 9001 certification were gaining popularity, with the latter being recently implemented in K-12 education in the United States. On the contrary, Six Sigma was underrepresented and was only used when the purpose of the evaluation was to determine the correct functioning of administrative units. Finally, they found little evidence mirrored either in the Malcolm Baldrige National Quality Award or in the AQIP.

Almost all the aforementioned methods come from the manufacturing industry, revealing the need for unambiguous methods and tools specifically designed for the service context, able to capture customer perceptions of the quality delivered in the service encounter. According to the literature (Ladhari 2009), one of the most popular scales used to measure service quality is the SERVQUAL model (Parasuraman et al. 1990, 1985). SERVQUAL operationalizes service quality by comparing the perceptions of the service received with the expectations. Since this scale was published, a number of variations flourished. In the specific context of HE, Brown and Mazzarol (2009) adapted the SERVQUAL scale and found that one of the most important antecedents of perceived value was the image of these institutions, whereas the perceived quality of people and processes, and the infrastructures and tangibles of the service had weak 
and vague impacts. Other adaptations of the SERVQUAL scale in HEIs include the works of Dib and Alnazer (2012), Dlacic et al. (2014), Hasan et al. (2009), Nadiri et al. (2009), Shaney et al. (2006), and Yeo and Li (2014). Sultan and Wong (2012) provide a comprehensive review of studies that, for the past fourteen years, have adopted the SERVQUAL instrument in a variety of contexts yielding in a number of different dimensions.

Further, a series of studies examine how universities perform using not just the SERVQUAL scale, but also comparing the results with other scales. In this direction, Abdullah (2006) tested and compared remarkably the relative efficacy of three measuring instruments of service quality: HEdPERF (Higher Education PERFormance), SERVPERF (SERVice PERFormance) and the moderating scale of HEdPERF-SERVPERF. More recently, Brochado (2009) compared the three scales: SERVQUAL, HEdPERF and SERVPERF (but only considered the perceptions of the service quality). Both studies converged in the difficulties resulting from the conceptual and empirical components of the measurement. The recent work of Yeo and Li (2014) also supports this lack of agreement.

Particularly relevant is the contribution made by professors Sultan and Wong. In the recent years these authors have published a number of papers (Sultan and Wong 2014, 2013, 2012, $2011,2010 \mathrm{a}, 2010 \mathrm{~b})$ that provide a complete model that includes not only a scale for assessing perceived quality, but also the antecedents and consequences of quality, such as satisfaction or intentional behavior.

\section{Antecedents of student satisfaction in $\mathrm{HE}$}

As mentioned before and according to the second objective of this study - finding how the perceived quality dimensions affected student satisfaction - it is worth reviewing the literature that has investigated potential antecedent conditions of student satisfaction. For instance, Alves and Raposo (2007) suggested a conceptual model to evaluate student global satisfaction, and 
found two main influencing factors: the image and the perceived value (consisting of customer expectations, and technical and functional quality perceived). The study also examines the consequences of student satisfaction, with findings revealing that a main implication is student loyalty, manifested in the form of word-of-mouth; in this respect, students become university brand advocates or detractors.

More recently, Tsinidou et al. (2010) identified the quality determinants in the Greek HE system. These authors measured the relative importance that students gave to different aspects related to service quality by running an analytical hierarchical process (AHP). The factors identified were: (i) academic staff, (ii) administrative services, (iii) library's services, (iv) curriculum structure, (v) location, (vi) facilities, and (vii) career prospects.

In this same vein of thought, Letcher and Neves (2010) carried out a stepwise regression analysis to determine students' "overall” satisfaction, measured via three dimensions: fulfilling expectations, value of investment, and recommendation of the program. Antecedents included eight different factors: (i) self-confidence, (ii) satisfaction with the curriculum, instruction and classes, (iii) satisfaction with quality of teaching of subject matter, (iv) satisfaction with extracurricular activities and career opportunities, (v) satisfaction with student advising, (vi) quality of teaching and instructor feedback, (vii) satisfaction with computing facilities, and (viii) satisfaction with student quality and interaction. Similarly, in a recent study, Mahmood (2011) analyzed the effect of factors - lecturers, research courses, facilities and supervisor support - on HE quality.

In recent years, Sultan and Wong have authored several studies suggesting new scales that try to overcome the limitations of previous studies. An example of this can be found in Sultan and Wong $(2013,2014)$, where the authors create a scale for perceived quality as a second order factor composed by three dimensions: (i) academic, (ii) administrative, and (iii) facilities. The scale consists in 26 items, 17 of them adapted from the extant literature and 9 items of new 
creation. Their findings reveal that past experiences are affecting perceived quality, introducing the temporal dimension in the model. Furthermore, satisfaction is found to be a direct consequence of perceive quality and this later, in its turn, is affecting behavioral intentions.

\section{Research method}

\section{Data collection and sampling}

To assess the perceived quality and the student satisfaction in HEIs, the authors signed an agreement with AQU (the Catalan University Quality Assurance Agency) to explore a survey that the AQU had sent to recent graduates of Catalan universities. The AQU is the primary instrument for quality promotion and assurance in the HE system in Catalonia.

To assess the quality provided by the Catalan HE system, in 2001, the AQU created a survey to be taken by undergraduate students that completed their studies at Catalan universities. The questionnaire was designed by the AQU based on the expertise and practical knowledge gained since its establishment. A number of external experts contributed to defining the instrument.

The questionnaire includes a section to collect 20 items to assess university degree quality. These items were gathered from previous studies performed by the AQU. All items were presented as statements to which respondents indicated their agreement/disagreement on a fivepoint Likert-type scale (from $1=$ strongly disagree to $5=$ strongly agree). Table 1 shows the items of the questionnaire related to the service quality perceived. The survey contains two additional sections: a series of questions referring to respondent socio-demographic information, and a final section with only one item aimed at assessing their overall satisfaction - also on a five-point Likert scale.

Insert Table 1 about here 
The Catalan HE system consists of twelve universities, seven of which are public, four private and one of a mixed nature. Catalan universities offer about 1,300 university program degrees, including bachelor programs, masters and doctorates, with 26,300 lecturing staff members and more than 237,000 students (AQU 2016). For the purpose of this study, we considered a survey launched in October of 2013 to all graduates of the Catalan HE system in the academic year of 2012/13.2,557 questionnaires were collected by creating an online survey that was made accessible to all recent graduates. Table 2 shows the demographic characteristics of the sample.

Insert Table 2 about here

According to AQU, 42,705 students finished their university studies in Catalonia in 2013. 15,151 of them obtained a bachelor degree (WINDDAT website). Remaining students were master students or students that obtained their title degrees under the previous legislation (before the implementation of the European Higher Education Area). The response rate is $16.9 \%$, which vouches for a sample error of $1.3 \%$, under a confidence interval of $95 \%$. The sample do not present bias in terms of gender, since the proportion of women that obtained the degree in Catalonia was $66.6 \%$.

\section{Method}

A two-stage analysis was proposed. In the first stage, we validated the UnivQual scale. To do this, we used a principal component analysis with varimax rotation to explore the natural dimensions among the 20 items of "perceived quality" included in the questionnaire. This method is appropriate when the objective is to minimize the number of factors emerged, resulting in an easier interpretation of these factors. This exploratory factor analysis (EFA) 
yielded three dimensions. Consequently, the dimensionality of each of these dimensions was the next step performed. Once the dimensions were clearly identified and characterized, we proceeded to assess their reliability and determine the internal consistency and divergent validity. Once all of the dimensions displayed correct psychometric properties, a confirmatory factor analysis (CFA) was performed, obtaining the validated UnivQual scale.

In the second stage, we examined the explanatory power of the different dimension of the UnivQual scale to explain student satisfaction, that is, how the perceived quality of the service delivered impacts on student satisfaction. For this purpose, a new model was tested where the dependent variable was the item "student satisfaction", regressed by the three factors of perceived quality of the UnivQual scale. The mediation effect of the perceived quality between expectations and satisfaction was also assessed. This last step was necessary to provide the nomological validity of the scale, as it provided new insights into the antecedents of student satisfaction.

\section{Results}

\section{Exploratory analysis of the UnivQual scale}

A Principal Components Analysis of the 20 items of perceived quality was performed. Both the Kaiser-Meier-Olkin statistic (0.937) and the Bartlett test $\left(\chi^{2}=7,174.6 ; 190\right.$ degrees of freedom; $p$-value $=0.000$ ) forecasted a good result for this analysis. These results confirmed a linear dependence between the variables and supported our view that the results were sound (Hair et al. 2010). Four factors emerged with eigenvalues greater than one (Kaiser criterion), which accounted for $60.04 \%$ of the variance in the sample. However, the last eigenvalue was slightly on the threshold (1.036) and it was dropped in order to simplify the analysis. Thereafter, a new exploratory analysis was performed, forcing it to extract three factors that accounted for the $54.86 \%$ of the variance. Table 3 shows the suggested factors, including the percentage of 
variance extracted. Only loads above 0.250 are shown. The criteria to retain items were: (i) loaded at 0.50 or more on a factor and (ii) did not load at more than 0.50 on two factors.

Insert Table 3 about here

The first factor refers to how the educational program (the bachelor's or master's degree) is designed and implemented (Letcher and Neves 2010; Tsinidous et al. 2010). In this factor, items relate to the general structure of the program, the coordination of contents among subjects, the equilibrium and balance of different subjects, the evaluation and assessment systems, the teaching methods, and the workload required by the different subjects that take part in the study plan. It also considers the overall satisfaction with regard to lecturers' activities (teaching duties and availability during office hours) and their role as student mentors. This factor accounts for $41.64 \%$ of the variance, and it is composed of seven items. Because all these items refer to the internal coherence of the academic offer and how to deliver it to students, we label this factor as "curriculum". It is important to note that actions to improve the records obtained in this factor are at the arm's length of faculty managers and instructors; in other words, deans, deputy heads, and lecturers are in charge of establishing how the courses are designed and resources assigned. A poor evaluation in this factor could signal that the way of doing things should be reconsidered.

The second factor gathers items that account for the impact of the training on the student. That is, how students assimilate the knowledge transmitted and in which level they acquire the skills developed throughout the academic program. Said differently, this construct mirrors how the academic program enables students to develop not only technical skills - those specific for the discipline - but also soft skills - such as communication, teamwork, critical thinking, decision-making, or leadership. Accordingly, the tag that best illustrates these characteristics is 
“skill development". This factor accounts for $7.39 \%$ of the variance, and comprises four items. We argue that, to some extent, students play a key role in this factor, in that, if they do not pay attention in class and do not complete the work assigned, they would be unable to acquire the knowledge transmitted and developed the expected skills. Notwithstanding, it seems fair to argue that if the curriculum is not well designed and implemented (factor 1), students would have difficulty in achieving the minimum level expected.

Lastly, the third factor accounts for $5.83 \%$ of the variance and includes six items that collect information about the general services, facilities and equipment of the university (Letcher and Neves 2010; Tariq 2011; Tsinidous et al. 2010). Particularly, it refers to a wide variety of "services and facilities", such as the library, classrooms, other teaching equipment, support for mobility programs, websites (usefulness of the information provided, timely updates), information regarding the enrollment process, grants and scholarships, etc. Overall, this factor is therefore, an assessment of the services deployed and conveyed by the university. Depending on the strategy of the university, these services could depend on central services or rely on each faculty/school. In other cases, the responsibility might be shared. Following the same reasoning as in the second factor, it could be argued that students need an appropriate environment in terms of physical facilities and services to make the most of their years of university studies.

\section{Validating the UnivQual scale}

To examine the unidimensionality of the aforementioned constructs, we ran three CFAs one for each of the constructs - using EQS 6.2 software. The three analyses extracted only one factor, indicating that our approach was sound. The internal reliability of these factors was then assessed and confirmed as the retained indicators exhibited loadings of .70 or higher. All items 
were statistically significant except UnQu2, UnQu3 and UnQu6 in the first factor and UnQu10 in the third. As the loadings of these items were close to 0.7 and their content was meaningful for the construct they represented, we decided to include them also in our scale. Future research might consider refining these items to improve their fit.

The internal consistency of the constructs reaffirmed our approach, obtaining values that exceeded the recommended threshold value of 0.7 for both the Cronbach's alpha coefficient and composite reliability (CR). The average variance extracted (AVE) also surpassed the cutoff point of 0.5 (Nunnally and Bernstein 1994) for all factors except the first (curriculum), although the result were close. To corroborate further the suitability of the items included in the first factor, we conducted several tests removing the items with a lower load. Results revealed that the Cronbach's alpha value did not improve; therefore, we decided not to exclude any items. Table 4 summarizes the reliability analysis of the three dimensions of perceived quality.

Insert Table 4 about here

Table 5 provides the results for the analysis of discriminant validity, which was performed using linear correlations or standardized covariances between latent factors by examining whether the inter-factor correlations were less than the square root of the AVE (Fornell and Larcker 1981). As seen in Table 5, the square roots of each AVE were greater than the offdiagonal elements. Thus, discriminant validity was confirmed.

Insert Table 5 about here 
In our final scale, the correlations between each item and the total corrected scales were high enough to denote a correctness of fit, and convergent validity was confirmed for all factors, obtaining statistically significant loads $(\mathrm{t}>2.58)$.

In the next step, we scrutinized the dimensions of UnivQual as dimensions of a CFA. The model was estimated using the robust maximum likelihood method from the asymptotic variance-covariance matrix. The fit indices obtained in the measurement model estimation showed that the variables converged toward the factors established in the CFA (see Table 6). $\chi^{2}$ Satorra-Bentler was 489.15, with 116 degrees of freedom and a p-value of $0.000 \cdot \chi^{2} / \mathrm{df}$ was 4.22, which was below the acceptable limit of 5, RMSEA was 0.063 and the CFI was 0.931 . Taking the significance of the robust $\chi^{2}$ statistic with caution and noting the global indicators, the global fit was acceptable (Hair et al. 2010).

Insert Table 6 about here

Based on this analysis, we can confirm that there are three main factors that capture student perceptions of service quality at HEIs: (i) curriculum, (ii) skill development, and (iii) services and facilities.

In the light of these factors, the first and third items act as "enablers" for the second factor. Following the EFQM's notation, this second factor can be interpreted as the "results" of the process. Consequently, we posit that our scale as in Model 1 has two "enablers" - curriculum, and services and facilities - that explain a "result" - skill development. Figure 1 graphically illustrates this logic.

Insert Figure 1 about here 
The goodness of the fit indices were the same as reported before; thus, the model had the same number of parameters between constructs: a covariance and two step coefficients from enablers to results. The covariance between the two independent constructs was 0.787 and robust, with a t-value $=7.778$. The standardized coefficient for "Curriculum" $\rightarrow$ "Skill development" was $0.553(\mathrm{t}$-value $=8.120)$ and the standardized coefficient for "Services and facilities" $\rightarrow$ "Skill development" was $0.226(\mathrm{t}$-value $=3.361)$. The three parameters were significant. These results signal that, rather than the provision of the services and facilities, it is how the academic program is structured and delivered that has a stronger impact on the skills that will be eventually acquired by students.

\section{Perceived quality dimensions as antecedents of student satisfaction}

Given the data on how students evaluated their whole experience at the university, a new model (Model 2) was proposed. With this model, we aimed to evaluate how each of the three dimensions in the UnivQual scale affected student satisfaction. Figure 2 shows that, in this case, we consider two "enablers" constructs - curriculum and services and facilities - and one "result" construct - skill development - as antecedents of student satisfaction. The fit indices obtained in this measurement model estimation were satisfactory: $\chi^{2}$ Satorra-Bentler was 579.96, with 130 degrees of freedom and a $p$-value of 0.000 ; therefore, $\chi^{2} / \mathrm{df}$ was 4.45 . RMSEA (0.065) and CFI (0.924) also displayed appropriate values.

Insert Figure 2 about here

Results in Table 7 show that the most important predictor of satisfaction is "curriculum". It is particularly important as it has a high and robust direct effect, but also an indirect effect 
through "skill development". On the contrary, "services and facilities" does not seem to play a role in student satisfaction.

Insert Table 7 about here

These results can be interpreted by analyzing the responsible agents in charge of monitoring each of the three dimensions. Adopting this perspective, our findings reveal that student satisfaction is highly dependent on (i) the ability of faculty managers to design attractive and sound academic programs and (ii) the expertise and knowledge of the lecturers in charge of transferring knowledge to students, and the teaching method used. Future research should be conducted to examine how universities should manage their human resources in order to maximize their limited resources. Going a step further in this direction, future studies might consider examining the internal coherence of the faculty staff and the duties to which they are assigned. It is of utmost importance to ensure a proper link between teaching and research activities to maximize the synergies between the different tasks faculty members are responsible for conducting (Horta et al. 2012).

As for the services and facilities, we can conclude that they have a secondary and weak effect, and only through the "skills development" factor (as an indirect effect). University services tend to be shared by different departments and faculties, meaning that there is a central unit in charge of ensuring their correct functioning and assigning to the different units (departments, faculties, schools) the corresponding resources. Therefore, the latter has little autonomy for governing the shared services and facilities. The overreaching conclusion is that, although to a lower extent, the central government is also shaping student satisfaction. 


\section{Discussion of the results}

This study proposes a scale (UnivQual) to evaluate student perceptions of service quality in HEI by considering not only the academic component of the service experience but also those factors that are part of the service package as implicit features (e.g. general services, facilities, equipment).

There are several conclusions that can be drawn from the analysis. The first finding is that the quality of an academic program is a multifactor construct. We propose a scale of 17 items arranged in three dimensions: curriculum, skill development, and services and facilities. These dimensions are, to some extent, aligned and complementing those found in previous studies. As for the first dimension, we argue that there is a general consensus in recognizing its importance when assessing the service delivered at HEI. The study of Sultan and Wong (2012, 2014) suggest accounting for the "academic service quality", a factor made up of 9 items that mainly refers to the lecturers' capacity to teach. In our scale, this information is captured in the "curriculum" dimension; nevertheless, we adopt a wider approach by also accounting for the internal consistency of the academic program. Tsinidou et al. (2010) also refers to this factor by including several items that inquire about the content, availability of information, and variety of the modules (both compulsory and elective) included in the syllabus. Similarly, Letcher and Neves (2010) consider the "curriculum, instruction, and classes" to be a relevant factor. These authors include 16 items that capture students' opinions with regards the coverage of different topics, grading, accessibility and responsiveness of instructors, and class sizes. Teaching quality is assessed as a separate factor. Another study that is worth mentioning is the work of Brochado (2009), which includes two dimensions that cover our first factor. While the "academic" dimension recalls students' opinions about the responsibilities of academics, in the "Program issues" dimension the academic offer and the reputation and flexibility of the programs is assessed. Similar to our approach, Jain et al. (2013) invites respondents to self-reflect about the 
learning outcomes and questions the meaningfulness of the instruction. To this end, they include several items regarding the evaluation system and the extent to which the content of the courses mirrors industry and social needs. All these works corroborate the validity of our first dimension (“curriculum").

The second dimension in our scale ("skills development") accounts for the knowledge, competences and skills acquired by students. Because of its intrinsic nature, we believe this dimension to go a step further, representing the transformation process (intellectual, behavioral and structural) students experience as a result of their learning experience at the university. Although the vast majority of previous scales developed in the HEI context do not consider this dimension, the work of Letcher and Neves (2010) supports our approach by including the "selfconfidence" dimension, which considers how the university has helped students developing useful skills and broadening their knowledge.

Lastly, literature supporting our third dimension ("services \& facilities") is rich. Nadiri et al. (2009) develop a scale based on administrative units such as services provided by the registrar, library, faculty office, rector office, dormitories, sports or health center. Alves and Raposo (2010) refer to this factor as the "functional service quality". Letcher and Neves (2010) use the terms "computing facilities" and "extracurricular activities/career opportunities" both falling within the domain of our third dimension. Likewise, Tsinidou et al. (2010) split this dimension into three: services, library and facilities. The work of Sultan and Wong (2014) also highlight the importance of this dimension. Particularly, the second dimension in their scale ("administrative service quality") collects information about administrative staff quality, while the third dimension accounts for the facilities and additional services offered by the university (e.g. library, catering, entertainment, etc.). We argue that both dimensions are somewhat covered in our third dimension, which incorporates items that consider both the quality and the state of those additional services and physical facilities embedded in a university setting. Given 
all the aforementioned considerations we conclude that our approach is sound and complements previous literature.

An in-depth analysis of the aforementioned three dimensions suggests considering two of these factors as "enablers" - curriculum, and services and facilities - for the "result" of the service provided -skill development. How the "curriculum" is designed and implemented strongly affects how students improve their skills (both soft and hard); however, the "services and facilities" play a second-order role, acting as an enabler of the learning process. Nevertheless, both factors are necessary and mutually reinforce each other.

In the second stage analysis, we provide evidence that student satisfaction is mainly explained by the content of the program and the learning process. To a lower extent, it also depends on the skills acquired by students after the years they spent at the university. On the contrary, the perceived quality of the services and facilities only has an indirect and marginal effect. Overall, these results suggest that one of the main actors responsible for improving student satisfaction is the faculty. On the one hand, the capacity to improve student perceptions in the "curriculum" dimension relies in the person in charge of managing the department or the faculty. Also at the individual level of the instructor different actions can be undertaken in order to improve the learning process of student and help them to better understand and learn the key concepts (i.e. introduction of new teaching methods, editing of new material, etc.). On the other hand, the "services \& facilities" dimension is highly tied to the institution strategic vision. University managers are typically in charge of determining how to allocate resources and which value-added services deliver. Listening to students' opinions may provide insights for managers when defining the global strategy of universities. Public and local authorities also have in their hands the shared responsibility in that they are in charge of allocating the public resources.

Taken as a whole, our findings reveal that listening to students' voice is critical, and that the three categories included in the UnivQual scale can provide meaningful information to 
university managers. If properly processed, data gathered can be extremely useful for making better informed decisions. Not all universities will focus their efforts and resources in the same direction. Universities need to first self-evaluate themselves, see their weaknesses and strengths and afterwards, elaborate the strategic plan that will dictate their future actions.

\section{Concluding remarks}

Two are the main contributions of this study. First, we have designed and validated a scale, UnivQual, to assess holistically student perceptions of the service quality delivered at universities. This scale presents the distinctive feature of being a useful instrument for assessing not just an individual subject or course, but for capturing student perceptions after completing their studies. Accordingly, it contains a number of items that refer to the entire academic program. Second, we test the explanatory power of the different dimensions of the UnivQual scale to predict student satisfaction.

We believe this paper provides an original contribution to the existing literature on assessing quality at universities from the student perspective. We hope our findings can be applied to help define attractive academic programs and provide useful insights on how the supporting facilities should be designed to allow students take advantage of their learning process at universities.

It must, however, be mentioned a series of limitations to the present study that, in turn, represent avenues for future research. This study has an exploratory nature; therefore, it is intended to build a foundation for future studies. The empirical application uses a sample from a particular country; consequently, results cannot be generalized across all HE systems. A recommendation for further studies relates to cross-country comparisons. Notwithstanding we are aware of the difficulties in obtaining homogeneous data. Another limitation that we consider worth mentioning relates to the absence of a longitudinal analysis that could have given a 
greater evolutionary perspective to the study. Future research might also examine the evolution of student perceptions of service quality in different stages of their college life. 


\section{References}

AQU Catalunya. (2016).

http://www.aqu.cat/site_related/enllacos/sistema_universtari.html\#.VsBJxVLt7GB. Accessed 8 February 2016.

Abdullah, F. (2006). Measuring service quality in higher education: HEdPERF versus SERVPERF. Marketing Intelligence \& Planning, 24(1), 31-47.

Ali, N. A., Mahat, F., \& Zairi, M. (2010). Testing the criticality of HR-TQM factors in the Malaysian higher education context. Total Quality Management, 21(11), 1177-1188.

Alves, H., \& Raposo, M. (2007). Conceptual model of student satisfaction in higher education. Total Quality Management, 18(5), 571-588.

Alves, H., \& Raposo, M. (2010). The influence of university image on student behaviour. International Journal of Educational Management, 24(1), 73-85.

Brochado, A. (2009). Comparing alternative instruments to measure service quality in higher education. Quality Assurance in Education, 17(2), 174-190.

Brown, R. M., \& Mazzarol, T. W. (2009). The importance of institutional image to student satisfaction and loyalty within higher education. Higher Education, 58(1), 81-95.

WINDDAT AQU Catalunya. http://winddat.aqu.cat/ca/ Accessed 1 November 2016.

Dib, H., \& Alnazer, M. (2013). The impact of service quality on student satisfaction and behavioral consequences in higher education services. International Journal of Economy, Management and Social Sciences, 2(1), 285-290.

Dlačić, J., Arslanagić, M., Kadić-Maglajlić, S., Marković, S., \& Raspor, S. (2014). Exploring perceived service quality, perceived value, and repurchase intention in higher education using structural equation modelling. Total Quality Management \& Business Excellence, 25(1-2), 141-157.

Fornell, C., \& Larcker, D. F. (1981). Evaluating structural equation models with unobservable variables and measurement error. Journal of Marketing Research, 18(1), 39-50.

Gruber, T., Fuß, S., Voss, R., \& Gläser-Zikuda, M. (2010). Examining student satisfaction with higher education services: Using a new measurement tool. International Journal of Public Sector Management, 23(2), 105-123.

Jain, R., Sahney, S., \& Sinha, G. (2013). Developing a scale to measure students' perception of service quality in the Indian context. The TQM Journal, 25(3), 276-294.

Kara, A., \& DeShields, O. W. (2004). Business student satisfaction, intentions and retention in higher education: An empirical investigation. Marketing Educator Quarterly, 3(1), 125 . 
Hair, J. F. J., Black, W. C., Babin, B. J., \& Anderson, R. E. (2010). Multivariate data analysis (7th ed.). Upper Saddle River, NJ: Pearson Prentice Hall.

Hasan, H. F. A., Ilias, A., Rahman, R. A., \& Razak, M. Z. A. (2009). Service quality and student satisfaction: A case study at private higher education institutions. International Business Research, 1(3), 163-175.

Hill, F. M. (1995). Managing service quality in higher education: The role of the student as primary consumer. Quality Assurance in Education, 3(3), 10-21.

Horta, H., Dautel, V., \& Veloso, F. M. (2012). An output perspective on the teachingresearch nexus: An analysis focusing on the United States higher education system. Studies in Higher Education, 37(2), 171-187.

Ladhari, R. (2009). A review of twenty years of SERVQUAL research. International Journal of Quality and Service Sciences, 1(2), 172-198.

Letcher, D. \& Neves, J. (2010). Determinants of undergraduate business student satisfaction. Research in Higher Education Journal, 6(March), 1-26.

Mahmood, S. T. (2011). Factors affecting the quality of research in education: Student's perceptions. Journal of Education and Practice, 2(11/12), 34-39.

Mergen, E., Grant, D., \& Widrick, S. M. (2000). Quality management applied to higher education. Total Quality Management, 11(3), 345-352.

Nadiri, H., Kandampully, J., \& Hussain, K. (2009). Students' perceptions of service quality in higher education. Total Quality Management, 20(5), 523-535.

Nunnally, J. C., \& Bernstein, I. H. (1994). Psychometric theory (3rd ed.). New York, NY: McGraw-Hill.

Parasuraman, A., Zeithaml, V. A., \& Berry, L. L. (1985). A conceptual model of service quality and its implications for future research. Journal of Marketing, 49(4), 41-50.

Parasuraman, A., Berry, L. L., \& Zeithaml, V. A. (1990). Guidelines for conducting service quality research. Marketing Research, 2(4), 34-44.

Petruzzellis, L., \& Romanazzi, S. (2010). Educational value: How students choose university. International Journal of Educational Management, 24(2), 139-158.

Quinn, A., Lemay, G., Larsen, P., \& Johnson, D. M. (2009). Service quality in higher education. Total Quality Management, 20(2), 139-152.

Rowley, J. (1997). Beyond service quality dimensions in higher education and towards a service contract. Quality Assurance in Education, 5(1), 7-14. 
Snipes, R. L., Oswald, S. L., LaTour, M., \& Armenakis, A. A. (2005). The effects of specific job satisfaction facets on customer perceptions of service quality: An employee-level analysis. Journal of Business Research, 58(10), 1330-1339.

Sohail, M. S., \& Shaikh, N. M. (2004). Quest for excellence in business education: A study of student impressions of service quality. International Journal of Educational Management, 18(1), 58-65.

Strathdee, R. (2011). Educational reform, inequality and the structure of higher education in New Zealand. Journal of Education and Work, 24(1-2), 27-48.

Sultan, P., \& Wong, H. Y. (2014). An integrated-process model of service quality, institutional brand and behavioural intentions: The case of a University. Managing Service Quality, 24(5), 487-521.

Sultan, P., \& Wong, H. Y. (2013). Antecedents and consequences of service quality in a higher education context: A qualitative research approach. Quality Assurance in Education, 21(1), 70-95.

Sultan, P., \& Wong, H. Y. (2012). Service quality in a higher education context: An integrated model. Asia Pacific Journal of Marketing and Logistics, 24(5), 755-784.

Sultan, P., \& Wong, H. Y. (2011). Service quality in a higher education context: Antecedents and dimensions. International Review of Business Research Papers, 7(2), 11-20.

Sultan, P., \& Wong, H. Y. (2010a). Service quality in higher education-a review and research agenda. International Journal of Quality and Service Sciences, 2(2), 259-272.

Sultan, P., \& Wong, H. Y. (2010b). Performance-based service quality model: An empirical study on Japanese universities. Quality Assurance in Education, 18(2), 126-143.

Tsinidou, M., Gerogiannis, V., \& Fitsilis, P. (2010). Evaluation of the factors that determine quality in higher education: An empirical study. Quality Assurance in Education, 18(3), 227-244.

Yeo, R. K., \& Li, J. (2014). Beyond SERVQUAL: The competitive forces of higher education in Singapore. Total Quality Management \& Business Excellence, 25(1/2), 95-123. 